\title{
LA ENTRAÑA CRIMINAL DEL SICARIO. ASPECTOS CRIMINOLÓGICOS DEL EJECUTOR EN UN HOMICIDIO POR MANDATO
}

THE CRIMINAL ENTRAÑA OF THE SICARIO. CRIMINOLOGICAL ASPECTS OF THE EXECUTOR IN A HOMICIDE BY MANDATE

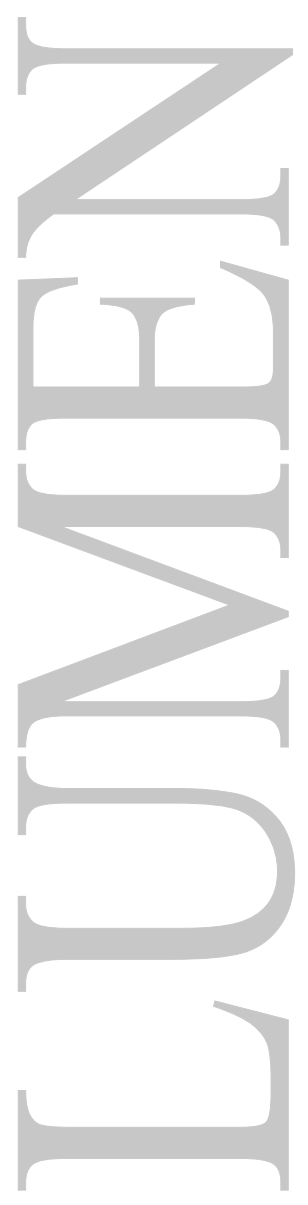




\title{
LA ENTRAÑA CRIMINAL DEL SICARIO. ASPECTOS CRIMINOLÓGICOS DEL EJECUTOR EN UN HOMICIDIO POR MANDATO
}

\author{
THE CRIMINAL ENTRAÑA OF THE SICARIO. CRIMINOLOGICAL ASPECTS OF \\ THE EXECUTOR IN A HOMICIDE BY MANDATE
}

Elvis Jorge Alcalde Muñoz

\begin{abstract}
RESUMEN:
El presente artículo, otorga una perspectiva criminológica sobre el sicariato en nuestro país, de manera especial muestra las principales características psicosociales de la persona que brinda su "labor criminal" a cambio de un beneficio, generalmente económico, lo que revela su poco aprecio por la vida de sus semejantes y la reprobación generalizada de una sociedad ávida de justicia y sanciones penales drásticas frente a la criminalidad. De otro lado, se aborda la problemática de los Sistemas de control informales, labor preventiva por parte del Estado y la importancia de reforzar la formación del individuo a través de la familia y entornos sociales primarios. La metodología a usar en el presente trabajo tiene matices teóricos, referidos al ámbito académico relacionado a la Criminología, analítico, deductivo, y explicativo.
\end{abstract}

\section{PALABRAS CLAVE:}

Criminología, sicario, psicopatía, prevención

\section{ABSTRACT:}

This article gives a criminological perspective on hired killers in our country, in a special way shows the main psychosocial characteristics of the person who provides his "criminal work" in exchange for a benefit, generally economic, which reveals his lack of appreciation for the life of their peers and the generalized reproach of a society hungry for justice and drastic penal sanctions against crime. On the other hand, it addresses the problem of informal control systems, preventive work by the State and the importance of strengthening the formation of the individual through the family and primary social environments. The methodology to be used in the present work has theoretical nuances, referred to the academic field related to Criminology, analytical, deductive, and explanatory.

\section{KEY WORDS:}

Criminology, hitman, psychopathy, prevention 


\section{Introducción}

Desde el Congreso Mundial de Criminología llevado a cabo en el año 2014 en México se estableció una discusión bastante interesante sobre la criminalidad común y los niveles de violencia alcanzados a nivel de Latinoamérica en la presente década, resaltando premisas y variables que se relacionan con juventud, modo de vida, pandillas y violencia, ello en base a los altos índices de inseguridad ciudadana que presentan nuestras ciudades pero también la especialización de la delincuencia, hecho que no podemos negar cada vez va en aumento. Es así que en el caso peruano la criminalidad común tiene un rostro juvenil, revelando edades entre 14 a 30 años sobre todo en tipos penales que lindan con los hurtos, robos agravados, delitos sexuales o y también homicidios agravados, en especial los asesinatos relacionados al mandato o encargatura que es el tema que nos convoca en el presente artículo. A comienzos del año 2010 se denunció a través de diversos medios de comunicación social la oferta de adolescentes y jóvenes que utilizaban las redes sociales para proponer la comisión de diversos delitos entre ellos homicidios o lesionar a cambio de dinero, hecho que si bien conmocionó a la opinión pública no se propuso en su oportunidad correctivos o medidas preventivas, lo que ocasionó con el paso de los años la materialización de estas conductas nocivas.

Si bien es cierto la fase externa del ilícito penal nos plantea la materialización de una conducta, la activación del principio causa-efecto, acción y reacción lo que en buena cuenta existe después de todo un desarrollo previo de maquinación y preparación que implica un proceso en el fuero interno que si bien este último no tiene relevancia punitiva por una ficción jurídica y también de garantías penales, revela la importancia de su análisis ya que sólo así podemos establecer actividad preventiva. Así, debatir sobre la mente humana y el mecanismo de engranajes que se suscita en ella desde la aparición del móvil criminal es vital. A nuestro criterio, no todo delito se inicia con la idea criminal, aunque constituye el primer engranaje del camino del crimen; en realidad todo delito se origina a raíz de un móvil, un motivo y depende de que tan poderoso sea, y desde luego que tan influenciable sea sobre el individuo, que haga nacer en éste la idea criminógena.

Pero desde luego, aparte del móvil es necesario precisar que el individuo normal puede ser influenciado fuertemente por el móvil, esa influencia lo puede determinar de manera instantánea o a largo plazo, pero otro factor o concausa para determinar el proceso en el fuero interno del individuo es si éste presenta algún proceso afectivo alterado o esté propenso a emociones violentas o por último, pueda tener rasgos o trastornos mentales importantes que provoque junto al móvil un efecto y desenlace devastador. Por ello, analizar y explicar la fase interna del delito es de suma valía, ello nos permitirá entender el delito, no justificarlo, pero a la par podremos establecer ajustes preventivos para disminuir a futuro los altos índices criminales de nuestra sociedad.

Dentro de los ilícitos penales dolosos se manifiestan los fueros internos y externos del delito, ello porque en estos tipos delictivos existe una planeación, planificación, un recorrido intencional que sigue la persona para consumarlo, a diferencia de los ilícitos impudentes o negligentes en que son inesperados y en éstos no podrían existir niveles de preparación o recorrido intencional previo. Así, dentro del fuero interno el primer engranaje que se analiza constituye la idea criminal pero como ya se dijo obedece siempre a un móvil, insignificante o no móvil al fin, por ello la ideación nace producto de algo que nos impacta, que nos conmueve, que nos perturba o que nos indigna, así la idea delictiva puede permanecer en la mente de la persona poco, mediano o mucho tiempo, unos minutos, un día, 10 meses, 3 años, etc, pero en algún momento pasamos de la idea criminal a un "segundo engranaje", éste lo constituye la deliberación que no es más que el sopesar, balancear los aspectos positivos y negativos (ventajas y desventajas) de cometer el delito. Este estado deliberativo también puede ser de tiempo indefinido y es crucial porque aquí es donde pongo en una balanza no sólo bondades y maldades de la comisión, sino también le doy un valor al móvil; también toman importancia los procesos afectivos, los estados de ánimo, las alteraciones emocionales, los trastornos mentales 
que pudiera tener el individuo, todo ello se sopesa en la deliberación para posteriormente tomar una decisión. Precisamente la resolución criminal es el último engranaje dentro del fuero interno, la decisión de cometer el delito o abstenerme, nótese aquí que desde la aparición del móvil hasta la resolución criminal pueden pasar minutos, pero también pueden transcurrir años.

Otro aspecto importante a resaltar con relación a la temática de nuestro artículo es que en el sicario su accionar delictivo es evidentemente doloso, se trata de un ilícito penal doloso y que según la legislación de cada país puede adoptar diversas denominaciones, se le ha llamado homicidio por mandato, homicidio por dinero, homicidio por lucro, homicidio por encargo, homicidio por contrato, sicariato, etc. Lo importante es tener presente que la particularidad dentro del fuero interno es que el sicario no maneja el móvil de fondo y eso es importante de entrada, precisarlo; la motivación de fondo y por la cual se organiza y planifica el hecho criminal la tiene el mandante o "autor intelectual". Aquí viene precisamente el gran reproche que recae sobre el sicario, que, si bien tiene un móvil, que no es el de fondo sin embargo, su motivación es económica: la obtención de una ventaja de algún tipo, lo que revela su predisposición por causar un mal sin el más mínimo sentimiento de culpa o reparos lo que en el fondo nos muestra un ser frio, insensible, y con poco aprecio por la vida. El presente trabajo precisamente otorgará una mirada al fuero interno de este ser humano, de este individuo que aprieta el gatillo no teniendo claro ni cimentada una motivación sólida más que el beneficio patrimonial u oneroso.

De otro lado, debemos tener presente que las figuras del Homicidio por encargo o sicariato en la mayor parte de legislaciones del mundo son consideradas como asesinatos o crímenes de meridiana y alta gravedad por lo que sus penas reflejan el desvalor y reproche que la sociedad otorga a estas conductas alevosas.

\section{Psicopatía y otras desviaciones}

La conducta humana tiene diversas variantes y se divide en conductas adecuadas y conductas desviadas; a su vez, dentro de estas últimas algunas son delictivas y otras son no delictivas, precisamente dentro de las delictivas está nuestro objeto de estudio debido a que, en el caso peruano, el homicidio por encargo está penalizado primero como asesinato y actualmente existe un tipo especial denominado "sicariato". Pero debemos poner especial atención precisamente en la denominación de conducta desviada, precisamente este término de "desviado" es apropiado debido a que no sólo obedece a una cualificación de la conducta del individuo sino también al probable trastorno psíquico que pudieran sufrir estos sujetos y que, si bien no lo hace inimputable en absoluto sin embargo, es importante tener presente para efectos criminológico y de política criminal preventiva.

Se debe tener en cuenta que en el fuero psíquico del individuo se producen dos procesos que los podemos delimitar con operaciones o mecanismos de la mente, el primero se refiere a los procesos afectivos que están relacionados con el mundo de los sentimientos, ello implica el amor en todas sus manifestaciones, el odio, el aprecio, etc; también se aprecian los estados de ánimos que tienen relación con la alegría, la tristeza, la melancolía, la euforia, el optimismo, y de otro lado también se encuentran las emociones y que abarcan por ejemplo el miedo, los celos, el enojo y por último, las pasiones que implican la inclinación fuerte por una actividad o servicio (fuerte inclinación por la ayuda social, por el arte, la docencia). Es decir como apreciamos, los procesos afectivos del individuo se van fortaleciendo y consolidando con sus antecedentes de vida (llámese entorno familiar, experiencias en la infancia, niñez, adolescencia, juventud), y que ya de adulto consolidan la personalidad. Por ello, así como se puede adquirir una personalidad sólida de adulto también pueden existir personalidades agresivas, violentas, extrovertidas, introvertidas, sumisas, influenciables, indiferentes frente a los demás, etc. Sin embargo, estos rasgos de la personalidad 
precisamente se deben a la formación y experiencias que ha tenido el individuo a lo largo de su vida.

Cuadro $\mathrm{N}^{\circ} 01$

\section{Los Procesos Afectivos}

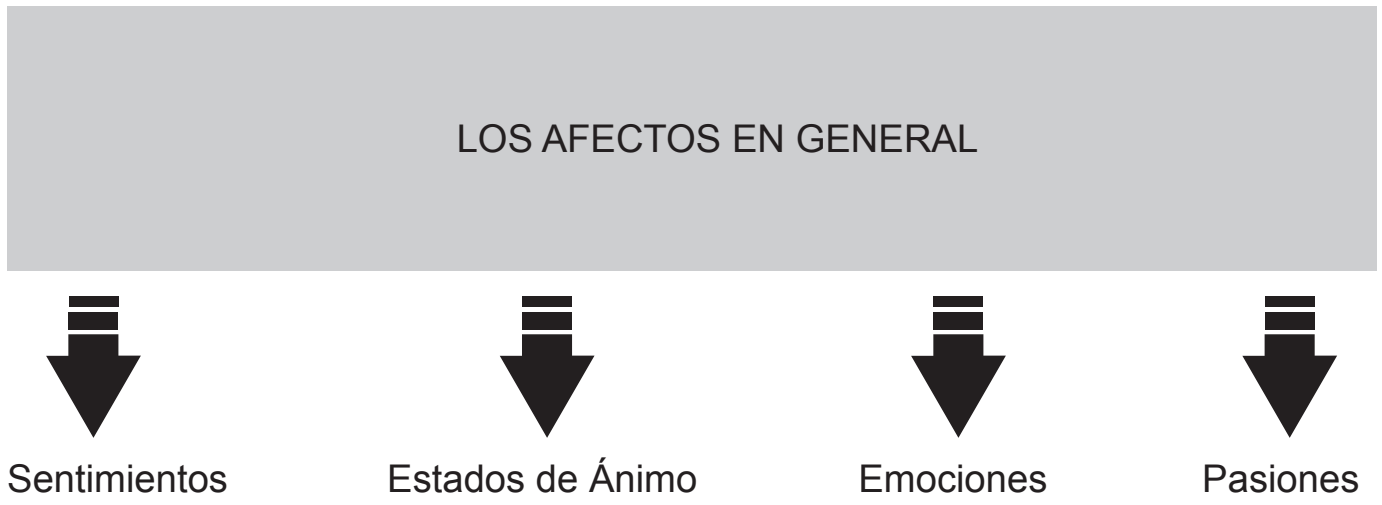

- Señala las diferentes variantes de los procesos afectivos y que pueden ser susceptibles en algún momento de nuestra vida de ser afectados por algún evento traumático, lo que ocasiona en el individuo periodos de alteración emocional ó anímica y que repercuten en nuestras actividades cotidianas.

De otro lado, se encuentran los trastornos o alteraciones de la mente que implica un nivel de afectación más grave, en el que existe sintomatología marcada donde resaltan ciertas características y conductas, unas más que otras; recordemos que algunas alteraciones constituyen verdaderos "cajones de sastre" como por ejemplo la histeria, por ello aquí debemos identificar 4 niveles: El primer nivel, los brotes psicóticos que como sabemos son los trastornos de la mente más severos donde existe un desfase con la realidad, hay un divorcio del plano real con lo que vive el individuo, y esto generalmente ocurre por los periodos de alucinación que sufre, especialmente a nivel auditivo, visual y sensorial. La corriente psicoanalítica en alguna oportunidad trató de explicar este trastorno como la famosa "ruptura del mundo psíquico" al tratar de eludir y caer en las perversiones o las neurosi; sin embargo, en la última parte del siglo $X X$ se reforzó la idea que este tipo de alteraciones psicóticas tienen una causa genética y que su producción obedece a transmisión hereditaria por lo que su identificación y tratamiento a temprana edad es clave para evitar un desencadenamiento nocivo y funesto en el futuro. Mucho se la ha identificado con la denominación de esquizofrenia y que estos cuadros en estadios avanzados están acompañados de paranoia o delirios de acoso, coacción, amenaza o persecución. Lo cierto es que para el Derecho penal, en países con tendencia europea continental, las infracciones dolosas que se cometan bajo el influjo de estos cuadros clínicos son consideradas como inimputables y funcionan desde el punto de vista de la teoría criminógena como causas de exculpación; por lo tanto, el individuo no respondería penalmente por el hecho delictivo sino que se le aplicaría una medida de protección o seguridad, en busca claro está, no de su resocialización sino técnicamente de su rehabilitación.

El segundo nivel está relacionado con las alteraciones neuróticas, pero son disfunciones mucho más leves que las primeras pero que de todas maneras implican una alteración en la vida del individuo, de manera especial en las interrelaciones que pueda tener tanto a nivel personal, familiar, laboral, amical, etc. Estos trastornos tienen que ver con conductas extrañas que realiza la persona, manías que adopta en su afán de sentirse mejor, regocijado, o respaldado emocionalmente pero ello debido generalmente, a recuerdos de eventos traumáticos que la persona no ha superado en su 
infancia, niñez o adolescencia. Para la Escuela psicoanalítica, la mente humana estaba conformada por 3 segmentos, lo subconsciente, lo preconsciente y lo consciente. Precisamente, el individuo que sufría estos episodios neuróticos traía de lo subconsciente a lo consciente esos hechos traumáticos y que generalmente estaban relacionados a eventos de abusos sexuales, agresión, violencia, etc. y que no habían sido adecuadamente superadas.

\section{Cuadro $\mathrm{N}^{\circ} 01$ \\ Naturaleza de las Alteraciones Psíquicas}

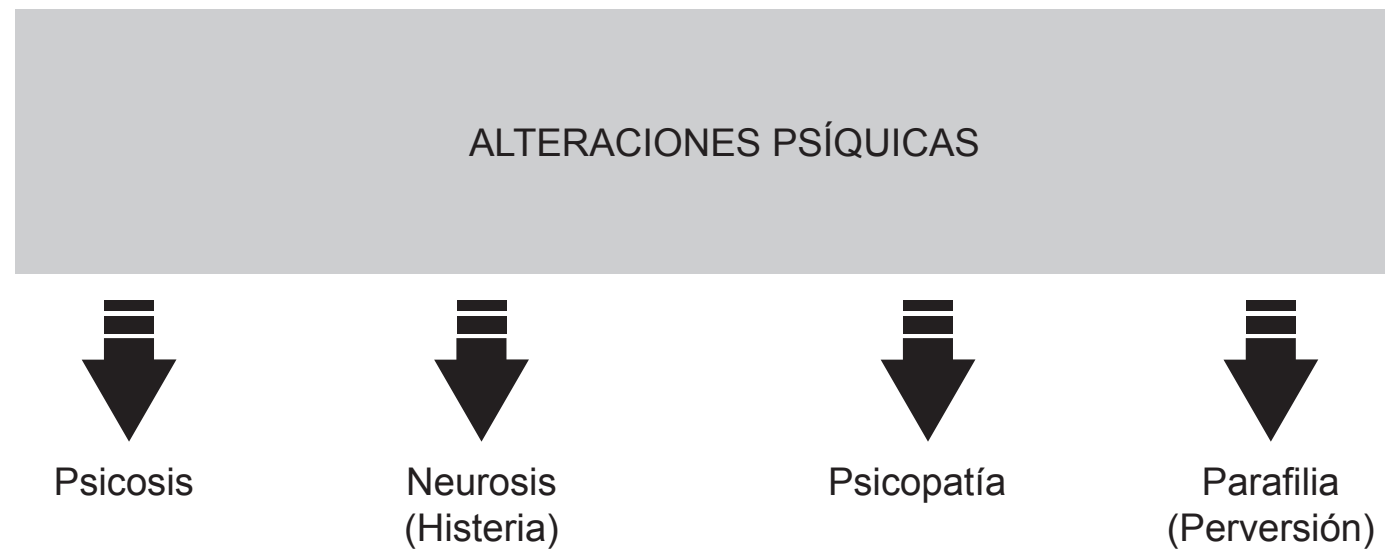

- Señala los principales niveles de alteraciones de la mente sobre los cuales se han agrupado las actuales clasificaciones de enfermedades mentales tanto de la Organización Mundial de la Salud, como la norteamericana.

Así también dentro de las neurosis existen diversas variantes que han sido clasificadas de acuerdo a la primacía de una sintomatología en particular. Así, las neurosis obsesivas compulsivas donde existe el recuerdo, al alteración psicosomática y la compulsión; de otro lado, también existe la histeria como una variante neurótica que como indicamos a través de la historia ha sido cuestionada como trastorno psíquico sobre todo, por su sintomatología física debido a que el padecimiento emocional se transforma incluso en dolor físico; por ello, hoy en día se la conoce como trastorno de conversión. La histeria ha causado mucha controversia y debate, para comenzar desde el nombre que ha adoptado y por el cual mucho se ha identificado como una alteración propia de la mujer sin embargo, hoy en día se acepta que puede ser sufrida por ambos sexos; es más, se le cambió de denominación a trastorno histriónico, porque una de sus principales características es la figuración y la necesidad de atención excesiva. El histérico necesita llamar la atención de manera excesiva, ser atendido, es por ello que en crisis puede llegar a cometer actos de figuración excesivos ya que a falta de estas atenciones, sufre. La literatura criminológica ha registrado muchos crímenes relacionados a lesiones dolosas, ilícitos contra el honor, e incluso homicidios debido a estas crisis histéricas.

Las psicopatías, Ilamadas también por un sector de la literatura psiquiátrica y criminológica, trastorno disocial de personalidad, constituyen alteraciones poco perceptibles por el entorno debido a que el individuo actúa con total conciencia y percepción de la realidad pero con el adicional de que en la gran mayoría de casos registrados tienen un coeficiente intelectual promedio y alto, asimismo son bastante sociables; sin embargo, carecen de sentimientos de bondad, altruismo y empatía para con sus semejantes. Es por ello que quienes las padecen son personas altamente peligrosas para la sociedad ya que son extremadamente manipuladores y pueden llegar a utilizar 
a sus familiares o seres cercanos para cometer actos criminales en favor de sus objetivos. Si bien es cierto se ha identificado a los psicópatas como personas que en sus antecedentes familiares han adolecido de una presencia paterna que los oriente y por el contrario han tenido una madre autoritaria, violenta, agresiva y castrante lo que al parecer ha ocasionado la acumulación de agresividad y frustración dentro de ellos. Estos individuos por lo general no tienen sentimientos de culpa frente al daño que ocasionan y son de muy difícil readaptación y por ello, la medicina en el campo neurológico se ha preocupado por su estudio y ha identificado un problema celular a nivel del cerebro prefrontal (lóbulo prefrontal) lo que estaría ocasionando dicho trastorno, ello en virtud a que se han observado sujetos que después de un accidente o daño a este nivel su conducta ha variado notablemente, presentando las características ya descritas. Lo cierto es que los psicópatas pueden llegar a manipular incluso a segmentos importantes de una población, a lo que se ha denominado sociopatías que son ya conductas más agravadas y perjudiciales para una sociedad. Tratadistas como Hare (1974), señalan lo siguiente:

El término psicópata se aplica a los individuos de comportamiento habitualmente antisocial, que se muestran siempre inquietos, incapaces de extraer alguna enseñanza de la experiencia pasada, ni de los castigos recibidos, así como también incapaces de mostrar verdadera fidelidad a una persona determinada. Suelen ser insensibles y hedonistas, de muy acentuada inmadurez emocional, carentes de responsabilidad y de juicio lúcido, y muy hábiles para racionalizar su comportamiento a fin de que parezca correcto, sensato y justificado. (p. 11)

El grupo de las parafilias también han recibido el nombre de trastornos psicosexuales y por el cual la Escuela psicoanalítica ha elaborado diversas interpretaciones para explicar su origen y fundamento, así dentro de este grupo se encuentran por ejemplo la pederastia, el exhibicionismo, el sadismo y el masoquismo, los trastornos de inversión, el fetichismo, etc. Así, su fundamento siempre ha girado en torno a un hecho traumático o experiencia castrante o sexual en las primeras etapas de la vida, llámese la infancia o niñez principalmente. Sin embargo, gran parte de estas conductas están penadas por las legislaciones penales del mundo, en especial la pederastia que la consideramos con el nombre de pedofilia que no es más que la conducta compulsiva de un individuo por yacer sexualmente con un niño o infante. Freud (1905), señaló sobre el trastorno pedófilo "excepcionalmente son impúberes objeto sexual exclusivo; en la mayoría de casos llegan tan sólo a serlo cuando un individuo cobarde acepta tal subrogado o cuando el instinto impulsivo inaplazable no puede apoderarse en el momento de un objeto más apropiado" (p. 159). Revelando así el padre del psicoanálisis, una desviación del instinto sexual que sufren estos sujetos. Muchos de estos trastornos son responsables en el rubro de tipos penales sexuales que por ejemplo en el caso peruano están regulados como delitos de violación sexual tanto de mayor de edad como menor de edad, acoso sexual, ofensas al pudor público, tocamientos indebidos no consentidos, violación a la privacidad o pornografía infantil.

\section{El Sicario y Trastorno Disocial de personalidad}

El Sicario constituye un personaje que aparece como ejecutor material de un mandato u orden en las organizaciones criminales internacionales y con mayor relevancia en las de tráfico ilícito de drogas, precisamente este tipo de modalidad delictiva, ejecución por encargo, nos ha procurado en países como el nuestro nuevas tendencias en la ejecución del delito donde el verdadero autor está escondido, y el ejecutor actúa por beneficio o dinero. Sin embargo, el sicario es un autor especial cuya particularidad se encuentra precisamente en la motivación (móvil), ya que éste se "ensucia las manos" por un móvil pecuniario, económico, a cambio de un beneficio, no posee el móvil primigenio llamado también "motivación de fondo". Esta circunstancia nos llama la atención y nos hace analizar dos cosas: Primero, la predisposición por matar por un fin lucrativo; y segundo considerar el matar a personas como un modo de vida o "trabajo". En el primer caso, para el 
sicario, la vida humana tiene un precio económico y puede ser vulnerada o extinguida a cambio de ese precio, lo que revela una entraña anética y de escasa importancia por la vida de sus semejantes, no revelando sentimientos de culpa o remordimiento por su accionar delictivo. Lo precitado muestra un escaso nivel valorativo y de poco significado intrínseco por la vida humana y estas características son propias de los sujetos que tienen rasgos psicopáticos o de trastorno disocial de personalidad, esto también se corresponde con la segunda característica el cual era "el matar como modo de vida o -trabajo-" ya que el sicario utiliza está actividad como un medio para agenciarse de dinero y subsistir revelando su predisposición a actividades ilícitas y su nivel de vida al margen de la ley dentro de una sociedad que se mueve en base a estándares y status de vida; así, en el sicario no han funcionado de manera asertiva los controles sociales informales llámese la familia, la escuela, los amigos por lo que sus conductas son desviadas y penadas, operando aquí el control social formal por parte del Estado represivo y sancionador ${ }^{1}$ (autoridad policial, Ministerio Público y Poder Judicial).

Así, Goppinger (1975), señalaba que las familias estructuralmente incompletas causaban un gran daño en la formación del menor:

Se trata de familias en las que alguna posición en el conjunto de papeles dentro de una familia no está ocupada (por lo general la de los padres). Se habla de desorganización estructural porque los restantes miembros de la familia tienen que encargarse, respecto a la sostenibilidad del hogar y la socialización del niño, lo que constituyen papeles diferentes a los acostumbrados. Con todo ello podrá quedar perturbado el proceso de socialización e influir sobre la conducta posterior del niño en el sentido de una conducta desviada. (p. 226)

De otro lado, el trastorno disocial de personalidad es una de las desviaciones que a lo largo de las décadas al igual que la histeria ha revelado una serie de sintomatología muy diversa sin embargo, hoy día se sabe que está referida a la psicopatía y que la sufren individuos que en buena cuenta no tienen alteración de la percepción; por el contrario, su coeficiente intelectual es bastante elevado, con una gran elocuencia y facilidad para manipular personas, si bien en muchos casos se los ha identificado con seres anéticos y poco sociables, creemos que no es una característica uniforme y que por el contrario en su mayoría tienden a tener un nivel de sociabilidad importante que les permite emparentar y asociarse con diversas personas que al final son manipuladas para sus fines ilícitos. No es extraño que los psicópatas siempre están involucrados en delitos de engaño, estafa, ardid o defraudaciones; sin embargo, pueden ser muy vehementes para conseguir sus objetivos, incluso no importándoles manipular a seres cercanos en busca de lo suyo. Otra característica del psicopático es su poca tolerancia ante la frustración que puede desencadenar en brotes agresivos; no es extraño encontrar una asociación entre psicopatía y violencia, de ahí que los estudios neurológicos sobre el particular han tratado de estudiar y asociar la zona prefrontal del cerebro con la amígdala y el hipotálamo cerebral como factores determinantes en este tipo de personalidad.

Así también otra característica importante de los sujetos psicopáticos es la ausencia de sentimientos de culpabilidad frente a un despropósito o un acto ilícito realizado, lo que comúnmente se denomina "falta de remordimiento" que en buena cuenta constituye la falta de sensibilidad frente al dolor ajeno, máxime si es el responsable de dicho sufrimiento, por lo que existe una indiferencia marcada en estos sujetos. Ello incluso se traduce cuando son investigados por la justicia y en sus declaraciones se refleja una narración de los hechos con una cotidianidad que sorprende.

${ }^{1}$ Precisamente, el Estado asume su rol conminativo, impositivo y sancionador a través de sus poderes u órganos facultados para tal fin, como acertadamente lo señala Montero Aroca (2016): “... el Estado, en aplicación del Derecho penal ya existente, porque él lo ha promulgado, asume seguidamente la titularidad exclusiva de lo que suele llamarse ius puniendi ..., pero bien entendido que éste no es derecho subjetivo atribuido al Estado, sino una potestad y deber" ( $p$. 99). Así, los controles formales por parte del Estado entran a participar de manera legítima para establecer mecanismos correctivos ante la conducta desviada tipificada. 
Por lo general, los sicarios o ejecutores materiales del Homicidio son sujetos sentimentalmente fríos, con ausencia de valores, plenamente conscientes de su accionar delictivo por lo que bien cabe situarlos en un altamente probable perfil psicopático o al menos, de rasgos que lindan con ello; no presentan otra sintomatología que pueda confundir su diagnóstico, como antaño se pensaba, e incluso se ha dicho que los denominados "disocial de personalidad" son de muy difícil readaptación, precisamente por la entraña de maldad que los domina.

Sin embargo, para las Corrientes psicoanalíticas el origen de estas desviaciones psicopáticas en el individuo obedecerían a malas experiencias no superadas en la infancia e incluso, se ha elaborado un perfil de estas personas en que se señala que tuvieron padres ausentes y madres castrantes, violentas y sumamente autoritarias lo que ocasionaría una predisposición a estas conductas sin embargo, hoy en día no debemos descartar una presunta influencia biológica y neurológica en estas desviaciones como se ha dejado ver en investigaciones entre los años 1950 a 1960 (P.D. McLean - 1952, J. Delgado- 1953, H.Ursin y B. Kaada-1960) relacionadas a agresividad, violencia, amígdala cerebral e hipotálamo. Pero en este aspecto creemos que, si bien el campo médico ha tratado de esbozar el fundamento de las causas que originan estas desviaciones sin embargo, el entorno social es fundamental para la consolidación de individuos disociales, máxime si no hay la capacidad de resiliencia para rehabilitarse.

\section{Tipo penal de Sicario y Políticas preventivas}

El artículo $108^{\circ}-\mathrm{C}$ del Código Penal peruano maneja la siguiente fórmula con relación al delito de sicariato: "El que mata a otro por orden, encargo o acuerdo, con el propósito de obtener para sí o para otro un beneficio económico o de cualquier otra índole ...". Este tipo penal fue incorporado al Código Penal precisamente a raíz de los casos de homicidios por mandato que se suscitaron en nuestro país entre los años 2015 a 2017 lo que ocasionó una gran conmoción social y en realidad, no teníamos ese tipo de modalidades con tanta frecuencia por lo que precisamente por un tema coyuntural, se acoge esta figura penal en nuestra legislación. Por otro lado, el tipo penal señalaba al sicario como autor directo del delito de sicariato; sin embargo, presentaba algunas deficiencias como por ejemplo, la falta de precisión sobre la calificación del mandante, si respondería como inductor o coautor del delito de sicariato, que hubiera sido oportuno realizar dicha disquisición al regular este tipo penal, ya que esta calidad no es tratada ni en el artículo $23^{\circ}$ de autoría, ni en el inciso 1 del artículo $108^{\circ}$ del Código Penal sobre homicidio por lucro. Otra situación peculiar ha resultado la tipificación de este delito de sicariato, pese al existir la figura de Homicidio por lucro, por lo que al parecer estarían coexistiendo dos figuras penales similares o idénticas; sin embargo, por el Principio de Especialidad ante un conflicto de leyes se podrá preferir a la ley especial, en este caso la del sicariato. Lo precisamos debido a que no existe una derogación expresa de la figura del homicidio por lucro.

Como ya en alguna oportunidad lo hemos comentado, no habría problema para la calificación del sicario, ya que su hecho es de autoría directa por el delito de sicariato, sin embargo, en cuanto al mandante, lo que algunos denominan autoría intelectual sí ofrece algunas controversias y ello debido a la doctrina que optemos para tratar de calificarla, así, si abrazamos la doctrina causalista, este mandante tendría que ser catalogado como inductor, debido a que éstos no admiten un autor fuera de la escena del crimen; sin embargo, para la corriente finalista del derecho penal, este mandante sería un coautor, ya que para esta doctrina si admite que el autor esté tras bambalinas, es decir lejos de la escena, En lo particular creemos que sería más apropiado catalogarlo como coautor conjuntamente con el sicario del delito de sicariato, atendiendo también a que nuestro Código Penal actual tiene una tendencia finalista. 
Cuadro $\mathrm{N}^{\circ} 03$

Funcionabilidad del Sicariato

ALTERACIONES PSÍQUICAS
2) Ejecutor (Sicario)
1) Mandante

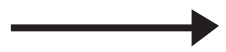

2) Intermediario

1) Mandante

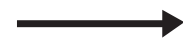

(Sicario)

- Establece la funcionabilidad del tipo penal de sicariato, estableciendo la figura básica del mandante y ejecutor, y también la otra modalidad en que se utiliza un intermediario para mediar entre el mandante y el ejecutor. En este caso se regula con mayor propiedad las modalidades delictivas, lo que antes era subsumido de manera implícita en el tipo penal de homicidio agravado por lucro.

Como lo señalamos, identificar a un sicario, capturarlo, iniciar su proceso penal y sentenciarlo, significa en el fondo que este individuo ha sido relegado, para él, el Control social informal no ha surtido ningún efecto y por lo tanto, no le han brindado las herramientas para su evolución adecuada y consolidación como persona de bien. En ese sentido, el filtro familiar (entornos sociales primarios), escolar, entorno social, no ha llegado hacia él con certeza y efectividad; así, debemos aceptar que la sociedad ha fallado en su legítimo derecho de formar sujetos de bien, con valores consolidados y firmes, y con respeto a sus semejantes. De esta manera, el Estado tiene una importante responsabilidad de brindar las herramientas necesarias para fortalecer el núcleo familiar, su consolidación en práctica de valores, ponderación, solidaridad, respeto y lealtad, tanto como ideales de justicia y equidad, recordando siempre que la familia es un factor de influencia y modelo decisivo en la formación de un individuo; por ello, las campañas de fortalecimiento a este nivel a través de los medios de comunicación deben ser periódicas y contundentes. Otro aspecto de política preventiva a resaltar está relacionado a la educación a nivel primaria y secundaria, donde el tutor y el especialista psicólogo tienen gran trascendencia en la formación del niño y adolescente lo que constituye el engranaje entre el Centro de estudios y la familia, y también ofrece el primer diagnóstico técnico sobre un probable brote de rasgos psicopáticos. Muchos tratadistas han resaltado la importancia de la formación de un individuo en las primeras etapas de su vida, tal es el caso de Jhon Bowlby (1986), Erik Erikson (1966) entre otros, tal es el caso del maestro Solís (2004), quien señala "en cierto modo por la razón específica que haya originado el hogar incompleto. Así, el abandono del hogar por uno de los ascendientes, puede repercutir en forma más negativa que el fallecimiento de uno de ellos" (p. 288).

En el sentido precitado, Winnicott (1967), señala:

Estos progresos, y muchos otros, pueden observarse durante el primer año de vida, aunque, desde luego, nada está establecido en esa época y casi todo puede perderse debido a 
problemas en la provisión ambiental después de esa fecha, o incluso ansiedades inherentes a la maduración emocional. No es extraño que el pediatra se sienta desanimado cuando intenta dominar la psicología del niño, brevemente bosquejada aquí. No obstante, no debe desesperar, pues por lo común puede dejar todo el problema en manos del niño, la madre y el padre. Pero, si se viera obligado a entrometerse en la relación madre-hijo, debe al menos tener conciencia de que es intruso y tratar de evitar toda interferencia que no sea imprescindible. (p. 28)

También las investigaciones de la psicóloga Shelley Taylor sobre la familia problemática o de tendencia criminógena han señalado lo siguiente:

Los niños procedentes de familias de riesgo suelen convertirse en adolescentes proclives al riesgo. Pueden fumar, drogarse y mantener relaciones sexuales tempranas, incluso cometer actos desadaptados; con frecuencia hacen todas estas cosas a la vez. Asimismo, los hijos de familias de riesgo que llegan a la adolescencia con escasos recursos sociales y emocionales y una dosis moderada de rechazo de sus semejantes gravitan hacia amigos similares. (Taylor, S, 2002, pp. 81 y 82)

De este modo, las políticas públicas por parte del Estado son vitales para fomentar un mayor fortalecimiento de algunos segmentos de la sociedad y que son especiales y tienen directa influencia en la formación del individuo, como son la familia, la escuela y el entorno social; por ello, a través de campañas sociales, publicidad televisiva, radial, programas de capacitación y concientización e inversión en sectores como educación y, mujer y poblaciones vulnerables se puede lograr un reforzamiento y consolidación del núcleo familiar, formación infantil, niñez y juventud. Ello aunado a un marco legal que propicie las condiciones para una activa participación de autoridades y población en su conjunto.

\section{Conclusiones}

A continuación, señalaremos algunos ejes centrales desarrollados en el presente artículo:

1) Un aspecto importante para realizar una diferenciación clara entre el mandante (autor intelectual) y el sicario es la fase interna del iter criminis y es precisamente, el móvil que origina la idea delictiva. El mandante tiene el móvil de fondo, la motivación principal que origina la verdadera idea criminal; sin embargo, el sicario tiene una motivación generalmente económica, de beneficio por materializar el hecho. Otro aspecto a resaltar es que en la Fase externa del delito el mandante no aparece en la escena, está lejos esperando la ejecución, mientras que el sicario es el autor material, el que necesariamente debe matar (consumar el delito).

2) Dentro de la mente humana existen dos alteraciones marcadas que pueden determinar la personalidad o enfermedad mental de un individuo, el primero está determinado por alteraciones de los procesos afectivos (llámese sentimientos, estados de ánimo, emociones, y pasiones) y el segundo está determinado por alteraciones de psiquismo (llámese trastornos mentales como la psicosis, neurosis, psicopatías y parafilias). Definitivamente, dentro de estos grupos hoy en día están inmersas una serie de variantes que son recogidas por las Clasificaciones de Enfermedades y trastornos mentales tanto la estadounidense como de la Organización Mundial de la Salud.

3) El sicario tiene una personalidad particular porque no es un delincuente común y corriente, constituye un criminal que demuestra su escaso aprecio por la vida humana, incluso su desprecio a niveles de valoración intrínseca, per se, tal es así que le pone un precio y se anuncia ofreciendo sus servicios para cegar la vida de un ser humano. Esta actitud le otorga 
esa particularidad de criminal feroz y de gran peligrosidad para la sociedad. De ahí que se lo puede catalogar como una persona con rasgos psicopáticos precisamente por su poco aprecio por la vida humana, carencia de sentimientos de culpabilidad, calculador e insensible frente al dolor ajeno, además de anético y falto de valores.

4) Debemos resaltar que si bien el tipo penal del artículo $108^{\circ}-\mathrm{C}$ del Código Penal ha tratado de poner un alto a la proliferación de crímenes por encargo estableciendo un tipo penal especializado y con sanciones elevadas sin embargo, existen precisiones a resaltar como la coexistencia de dos delitos similares como es el caso del Homicidio por lucro y el sicariato pero como ya señalamos puede resolverse bajo el principio de especialidad cuando existe conflicto aparente de leyes. Así también, se debió resolver la cualificación que le corresponde al mandante (autoría, coautoría o inducción). Circunstancia que como ya lo dijimos se trataría de coautoría.

5) Finalmente, si bien es cierto que la labor legislativa, conminativa, y sancionadora le compete al Estado y sus poderes, sin embargo constituye una reacción ex post, y tenemos que decirlo que lo ideal es la reacción ex ante es decir antes que los altos índices de sicariato nos desborde, por ello la labor preventiva es fundamental a través de las políticas públicas asertivas también de concientización, explícita, en que la población entienda la importancia de una adecuada formación del individuo dentro de la sociedad, sólo así disminuiremos los altos índices del delito pero claro está, constituyen soluciones de largo aliento, no inmediatistas, mientras que la sanción punitiva es mediática, en el fondo sólo paliativa.

\section{REFERENCIAS}

- BOWLBY, J. (1986) Vínculos afectivos: Formación, desarrollo y pérdida (Título Original: The Making and Breaking of Affectional Bonds, 1979; Traducido por Alfredo Guera Miralles), Madrid - España: Ediciones MORATA S.A.,

- $\quad$ ERIKSON, E. (1966) Infancia y Sociedad (Título Original: Childhook and Society; Traducido por Noemí Rosemblatt), Buenos Aires - Argentina: Ediciones Hormé S.A.E., Distribución exclusiva Editorial PAIDÓS.

- $\quad$ FREUD, S. (2002) Tres Ensayos para una Teoría Sexual (Título Original: Drei Abhanulungen zur sexual theorie, 1905; Traducción cedida por Editorial Biblioteca Nueva S.L; Traducido por Luis López Ballesteros y de Torres), Barcelona - España: Editorial RBA Coleccionables S.A.

- $\quad$ GOPPINGER, H. (1975) Criminología (Título Original: Kriminologie, Eine Einfúhrung, 1971; Traducido por María Luis Schwarck e Ignacio Luzarraga Castro), Madrid- España: Editorial REUS S.A.

- HARE, R.D. (1974) La Psicopatía - Teoría e Investigación, Barcelona - España: Editorial Herder.

- MONTERO AROCA J. (2016) El Derecho Procesal en la Encrucijada de los Siglos XX y XXI. Tres ensayos: Uno general y dos especiales, Lima - Perú: Fondo Editorial de la Academia de la Magistratura.

- $\quad$ SOLíS A. (2004) Criminología - Panorama Contemporáneo, Lima - Perú: Editores ByB, 4ta edición.

- TAYLOR, S.E. (2002) Lazos Vitales (Título Original: The tending instinct how nutring is essential for who we are and how we live; Traducido por Carmen Martínez Gimeno), MadridEspaña. 